\title{
A Venture to the Latest Robotic Technological Research: A Review
}

\author{
Prarthana BK*, Bhavana Y and Mani Shankar N \\ Department of Mechanical Engineering, SNIST, India
}

\begin{abstract}
Robots made its place in the pre $20^{\text {th }}$ century era as a part of an entertaining tool who never thought it could have any sensational role in today's life. From the baby's toy to the current sensor bots and much more advanced innovations as such have made man's life much easier, luxurious and accurate outcomes. Thus this field is currently expanding and enormously growing in the way nobody can just estimate. This field has shown much of profit zone and promising outcomes which have benefited many colossal arenas. This successive generation of Robots has challenged the current scientists and is welcoming the new ideologies and technologies to improve the functioning for a better tomorrow.

This current review tries to put an effort in understanding the advancements that has taken place in the past few decades to the date. It tries to bridge up the gap and helps the current budding scientists to understand the present scenario who can challenge the enormously improving technologies and make much more advancements in this field.
\end{abstract}

Keywords: Robotic technology; Recent advancements; Latest research; End effectors; Robot programming languages

\section{Introduction}

The robotic history has its roots since ancient myths and legends. Modern concepts began when industrial revolution allowed the use of complex mechanics. After 1920s human sized robots were developed with the capacity for near human thoughts and movements. Robots were first used in industries for manufacturing tasks without the need of human assistance. Digitally controlled robots and robots making use of artificial intelligence started to develop since 1960s.

Can we ever imagine that the origin of robotics have begun from 200 BC? Archytas built a mechanical wooden bird "The Pigeon" propelled by steam around 350 BC. In 1921, Karel Capek came up with word robot for his intelligence, artificially created person for the first time in his play. Though the concept of robot was around since ancients, modern day robot was born with the arrival of computers in 1940s. The robot became a popular concept from late 1950 onwards. Industrial robots do not have human like appearance. They are computer controlled manipulators. Robots were created to help humans. Robots can do even those tasks which human cannot do. Engleberger modified the earliest robots invented by George C. Devol into industrial robots and formed a company called Unimation to produce and market the robots. For his efforts and successes, he is known as "the Father of Robotics" in the industry.

Robots can be of various types like autonomous, remote controlled or semi autonomous. Robots have replaced humans in the assistance to perform those repetitive and dangerous tasks which humans prefer not to do, or are unable to do due to size limitations, or even those such as in outer space or at the bottom of the sea where humans could not sustain the extreme environments. Robots in earlier ages were used primarily for entertainment purpose. In today's modern life, technology has contributed in many ways to comfort people's lives. Especially robotic systems with an artificial intelligence have many industrial applications and have become increasingly important for some people. From $20^{\text {th }}$ century onwards the development of industrial robots changed the structure of society and allowed for safer conditions for labor. Industry has benefited drastically from the robotic work force. Automated machines have taken the dangerous jobs from humans and allowed greater productivity. Farmers have taken advantage of this new robotic technology with automated harvesters, the medical industry benefits from advancements in assisted surgical robotics. IBM runs a "lights off" factory in Texas, USA with an idea of a factory without human workers, which is staffed by fully autonomous robots making keyboards. Among the various programs launched by the currently military in the field of robotic technology, the most successful one was the predator and Reaper unmanned aerial reconnaissance vehicles which allowed only a pilot to control the robot from vast distances. The major advantage of these vehicles being high-altitude surveillance for long periods with no support to a live pilot, and during emergencies the planes can launch with small strikes on targets in zones which couldn't be operated by normal aircrafts.

As a result of artificial intelligence development as well as advances made in the robotics field the interaction between robots and humans is becoming stronger as they have become an absolutely essential tool in ensuring the quality in our lives. The advent of robots is quickly becoming an intrinsic part of our daily lives. Understanding the advancements in the current scenario of robotic technology, which is not just a subject but a vast field that is exploring within its colossal innovations. This paper tries to make an effort in the current advancements of various applications of robotic technology.

\section{An Introduction to Advanced Sensors}

The fields of robot sensing have created a boom and shocked many scientists for this innovative technology. Literature suggests that sensors are commercially available as optical, inductive, capacitive, resistive,

${ }^{*}$ Corresponding author: Prarthana BK, Department of Mechanical Engineering, SNIST, India, E-mail: prarthanabk17@gmail.com

Received December 28, 2012; Accepted March 08, 2013; Published March 11 2013

Citation: Prarthana BK, Bhavana Y, Mani Shankar N (2013) A Venture to the Latest Robotic Technological Research: A Review. Adv Robot Autom 2: 103. doi:10.4172/2168-9695.1000103

Copyright: (C) 2012 Prarthana BK, et al. This is an open-access article distributed under the terms of the Creative Commons Attribution License, which permits unrestricted use, distribution, and reproduction in any medium, provided the original author and source are credited. 
acoustics, magnetic, piezoelectric sensing principles and experimental transducers. Recently wireless sensor networks have become forefront in scientific niche (Figure 1). The major applications of this wireless sensor networks is the effort of engineering smaller sized devices and increasing the accuracy within the small and the smallest designed equipments. The recent robot invented that behaved like human included the key features like computers, sensors, auxiliary equipments and effectors which reported the major advantages like performing tasks similar to humans in unpredictable conditions. Anyhow intelligent robots are on great demand. Intelligent robots can be manufactured by manipulating adaptive control, mobility, robot programming languages, end effectors, manufacturing process planning and mobility. The major challenge to any scientist is to manufacture robot with low cost, high efficiency with more functional applications. The scope of robotic technology is vast which includes force control, wireless communication, safe control, $3 \mathrm{D}$ vision, multi robot control and remote robot supervision which could be a new career for budding engineers. Model based control has now been designed to control the industrial robots which are refined accordingly to improve the functionality when required. Driving forces management could be engineered in robots to have wide applications like assembling, heavy gadgets, automobiles or other machineries or as such. Micro robots add to one more discoveries to have its application in research arena to make cost effective in small scale industries.

MARIE (mobile and autonomous robotics integration environment), has multiple applications to operate multiple machines, operating systems by mobile integrated system. Latest technology involves replacement of thousands of pressure sensors with rubber pressure sensors to reduce the cost which has application as artificial skin [1-7]. Thus decreasing labor and efficiency with much outcome in limited time is the greatest advantage in the advancements of the robotic gadgets.

\section{Basic Improvements Concerned to Manufacturing Industry}

Robots have been recently introduced into the manufacturing technology. Robots perform wide range of functions such as manipulating a tool or handling the work piece [8]. Programming and maintenance are the only human tasks associated with robot installations. An intelligent and flexible robot is considered as a general purpose machine system that may include auxiliary equipment, sensors, computers and effectors. Such a robot should be able to perform

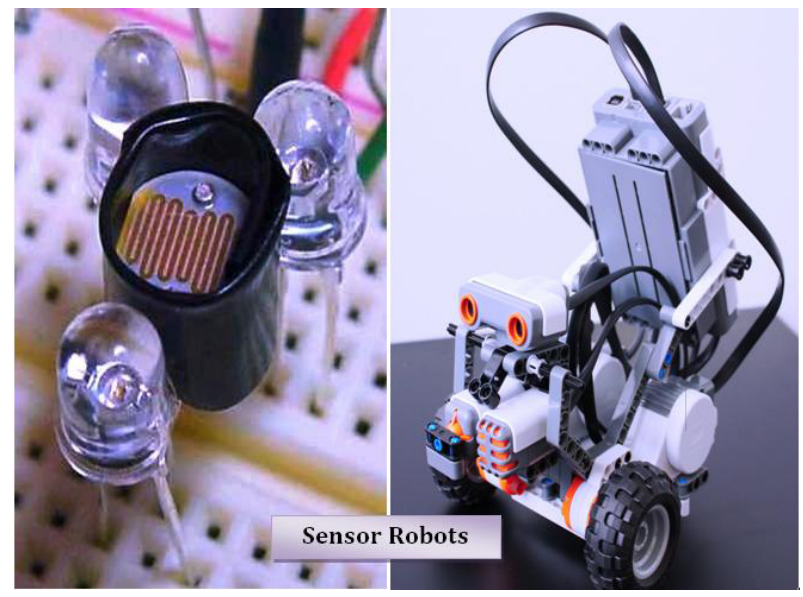

Figure 1: this figure is a view of model sensor bots. variety of tasks like a human under any unpredictable conditions [9]. The robotic system in hull grit blasting which has high quality surface preparation reduces wastage to a large extent without any emission to the environment. It is a fully automated environmental friendly system with cost effective technology [10]. The service robots such as the current floor cleaning robot were developed mainly on the human factors [11]. There are many institutions like German Aerospace Centre (DRL) Institute of Robotics and Mechatronics, KUKA Robotics GmbH and German robot manufacturer that support the researchers who are aiming to take up as a career [12]. Design approach is the fundamental key in modular robots which consists of end effectors, links and joints for performing multi-operational tasks [13]. Jean-Daniel et al. [14], in a study says that with just a language knowledge and visibility to the behavior of the robot today it has been an enormous robot community being developed.

\section{With Reference to Computer Applications}

A complex adaptive system (CAS) understands the complexity in natural systems. In this research the computer experiments led to the development of mathematical as well as computational techniques which are applicable in designing distributed control systems based complex system model which is composed of intelligent, autonomous and multiple agents [15]. Architecture and architecture styles are chosen for particular applications based on performance in previous work analysis on computer architecture design for robotics [16] Telerobots are those service robots which keeps the human workers away from the high radiation areas. The reuse of software components has been the major advantage of teleoperation in modular architecture [17]. Experimental results conducted at Robotics and Automation Laboratory at Michigan State University and Communication and Robotics Laboratory at Oakland University reveals that internet based teleoperation systems provides various technical challenges which have profound impact on day to day human life style [18].

\section{Current Traditions in Various Applications}

The introduction of robotic technology in food industry has made the competitive and repetitive tasks simpler and also cost effective [19]. The robot takes the visual input and reasons the shape of the object and decides the best stable grasp online [20]. Robot control is the key technology that could be engineered in food industry [3]. The automatically climbing robot finds applications in industrial fields like construction and shipbuilding where maintenance work and inspection involve highly dangerous manual operations [21]. Climbing robots are developed for different applications ranging from cleaning to inspection to reach construction. Secure gripping force with lightweight mechanism is the key for proper adhesion to the surface [22]. Robots afford better human safety in workplaces where traditional vehicles are unable to reach. Gecko inspired wall climbing robots (Figure 2) which has low cost operations are used in many applications such as repair, inspection, exploration and cleaning [23]. Studies made on past and ongoing research projects in micro, macro and bio robotics reveal that these three areas of robotics have potential to provide better improvements to the present state of art of medical technology [24].

The introduction of robots with new technology has high implication such as skill requirements, investments and broader social issues. Adoption of robots in different industries varies accordingly with their applications [25]. Summary robots are used under conditions where human productivity is less or requires high quality of work. This robot has a potential application on the building site. Field robots work under any environment such as under water, on farms, in forests, 


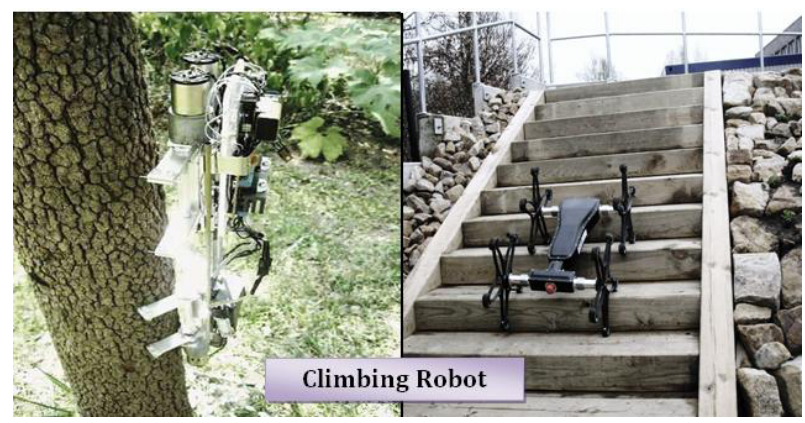

Figure 2: a glance of climbing bot.

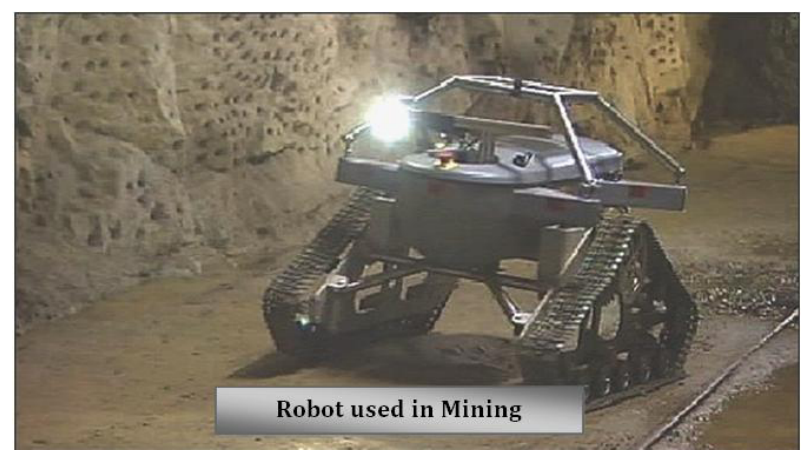

Figure 3: bot used for mining purpose.

in mines and in the air (Figure 3). A study by Chuck Thorpe Hugh Durrant-Whyte gives better ideas for design and development [26]. The space manipulation and the different class of applications like surface mobility in using polybot as it is having significant potential [27]. Miniature autonomous robots are capable of fast operations at molecular scale. Introduction of these robots in nanofactories can easily predict the exact shape and various components of nanofactories which operate at nanoscale [28].

Literature reveals that the use of robotic system in agricultural field like grass cutting on golf courses, robotic weeding in high value crops and crop scouting in cereals are more economically feasible than conventional systems [29]. Reuse of software in applications of robots is limited which is a key problem in software development of robotic system. So, software engineering techniques are implemented in industrial applications [30].

\section{Conclusion}

As the society is constantly and consistently transforming in short span is a symptom of development in the technology. Generation is growing more competitive, challenging and so the advancements are making a boom in the current scenario. Luxuries and comforts are the main cause for the new innovations with time compatibility and less labor. One such instrumental tool is robot. The current paper tries to accumulate some knowledge and information in concerned to the advancements in the robotic technology. It covers major industries and scientific areas to give a brief idea in the latest happenings of the research.

\section{References}

1. Arampatzis Th, Lygeros J, Manesis S (2005) A Survey of Applications of Wireless Sensors and Wireless Sensor Networks. Proceedings of the 2005
IEEE International Symposium on, Mediterrean Conference on Control and Automation.

2. Torgny B (2007) Present and future robot control development- An industria perspective. Annual Reviews in Control 31: 69-79.

3. Wildberge MM (1997) Complex adaptive systems: concepts and power industry applications. Control Systems 6: 77-88.

4. Caprari G, Balmer P, Piguet R, Siegwart R (1998) The autonomous micro robo "Alice": a platform for scientific and commercial applications. Proceedings of the 1998 International Symposium on Micromechatronics and Human Science, Japan.

5. Arampatzis T, Lygeros J, Manesis S (2005) A Survey of Applications of Wireless Sensors and Wireless Sensor Networks. Proceedings of the 2005 IEEE International Symposium on Intelligent Control, Cyprus.

6. Cote C, Letourneau D, Michaud F, Valin JM, Brosseau Y, et al. (2004) Code reusability tools for programming mobile robots. (IROS 2004). Proceedings. 2004 IEEE/RSJ International Conference on Intelligent Robots and Systems, USA.

7. Someya T, Sekitani T, Iba S, Kato Y, Kawaguchi H, et al. (2004) A large-area flexible pressure sensor matrix with organic field-effect transistors for artificial skin applications. Proceedings of the National Academy of Sciences of the United States of America, USA.

8. Edwards M (1984) Robots in industry: An overview. Applied Ergonomics 15 45-53.

9. Torgny B (2007) Present and future robot control development-An industrial perspective. Annual Reviews in Control 31: 69-79.

10. Leung SS, Shanblatt MA (1988) Computer architecture design for robotics Proceedings of IEEE International Conference on Robotics and Automation, USA.

11. Balaguer C, Gimenez A, Pastor JM, Pardon VM, Abderrahim M (2000) A climbing autonomous robot for inspection applications in 3D complex environments. Robotics 18: 287-297.

12. Amit G, Ning Xi, Elhajj IH (2005) Internet based robots: applications, impacts challenges and future directions. Advanced Robotics and its Social Impacts 2005. IEEE Workshop on 73-78.

13. Warszawski A (1986) Robots in the construction industry. Robotica 4: 181-188

14. Jean-Daniel Dessimoz, Pierre-François Gauthey RH3-Y-Toward a Cooperating Robot for Home Applications.

15. Peter J Wallin (1997) Robotics in the food industry: an update. Trends in Food Science \& Technology 8: 193-198.

16. Dario P, Guglielmelli E, Allotta B, Carrozza MC (1996) Robotics for medical applications. IEEE Robotics \& Automation Magazine 3: 44-56.

17. Mark Y, Kimon R, David D, Ying Z, Craig E, et al. (2003) Modular Reconfigurable Robots in Space Applications. Autonomous Robots 14: 225-237.

18. Bernardine DM, Dani G, Anthony S. Market-Based Multirobot Coordination For Complex Space Applications

19. Iborra A, Pastor JA, Alvarez B, Fernandez C, Merono JMF (2003) Robots in radioactive environments. IEEE Robotics \& Automation Magazine 10: 12-22.

20. Benhabib B, Dai MQ (1991) Mechanical design of a modular robot for industrial applications. Journal of Manufacturing Systems 10: 297-306.

21. Silva MF, Machado J, Tar JK (2008) A Survey of Technologies for Climbing Robots Adhesion to Surfaces. IEEE International Conference on Computational Cybernetics.

22. Hirzinger G, Bals J, Otter M, Stelte J (2005) The DLR-KUKA success story: robotics research improves industrial robots. IEEE Robotics \& Automation Magazine 12: 16-23.

23. Fernandez-Andres C, Iborra A, Alvarez B, Pastor JA, Sanchez P, et al. (2005) Ship shape in Europe: cooperative robots in the ship repair industry. IEEE Robotics \& Automation Magazine 12: 65-77.

24. Fleck J (1984) The adoption of robots in industry. Physics in Technology 15: 1. 25. Schofield M (1999) "Neither master nor slave...". A practical case study in the 
Citation: Prarthana BK, Bhavana Y, Mani Shankar N (2013) A Venture to the Latest Robotic Technological Research: A Review. Adv Robot Autom 2: 103. doi:10.4172/2168-9695.1000103

Page 4 of 4

development and employment of cleaning robots. Proceedings of 7th IEEE International Conference on Emerging Technologies and Factory Automation, Spain.

26. Chuck Thorpe Hugh Durrant-Whyte (2006) Field Robots 1-11.

27. Yim M, Roufas K, Duff D, Zhang Y, Eldershaw C, et al. (2003) Modular Reconfigurable Robots in Space Applications. Autonomous Robots 14: 225-237.
28. Sylvain M, Ian $\mathrm{H}(2002)$ Nanofactories based on a fleet of scientific instruments configured as miniature autonomous robots. Journal of Micromechatronics 2 : 201-214.

29. Pedersen SM, Fountas S, Have H, Blackmore BS (2006) Agricultural robotssystem analysis and economic feasibility. Precision Agriculture 7: 295-308.

30. Iborra A, Caceres D, Ortiz F, Franco J, Palma P, et al. (2009) Design of service robots. IEEE Robotics \& Automation Magazine 16: 24-33. 